\title{
Psychometric Properties of Spence Children's Anxiety Scale (SCAS)
}

\author{
Cemaliye Direktör \\ Department of Psychology, European University of Lefke, NORTH CYPRUS \\ Nergüz Bulut Serin \\ Department of Psychological Counselling and Guidance, European University of Lefke, NORTH CYPRUS
}

Received 17 April 2017 • Revised 18 July 2017 • Accepted 15 September 2017

\begin{abstract}
The aim of this study is to explain the validity and reliability of the SCAS translated into Turkish language, as well as testing the validity of the 6-factor model among the Turkish Republic of Northern Cyprus (TRNC) population. The sampling group consists of 461 students studying in the 4th and 5th grade of 11 primary schools selected randomly among 112 primary schools in Northern Cyprus under the Ministry of National Education. $48.80 \%$ of these students were female $(\mathrm{N}=225)$ and $51.20 \%$ were male $(\mathrm{N}=236)$. The age of the children ranged from 9 to $12(X=9.89, S=0.69)$. Exploratory factor analysis was used in order to assess the validity produced by the six-factor model. The confirmatory factor analysis results with six-factor model resulted in a good fit to the data. The Cronbach's Alpha value of the scale was .83 and the split half value was .80 . The correlation between the social phobia scores, which is a sub-scale of SCAS, and Social Anxiety Scale for Children was studied and it was observed that the correlation coefficient was found as .523 ( $p<.001)$. The MANOVA revealed a significant multivariate main effect of the gender. These results suggested that girls had significantly higher levels of anxiety, social phobia and physical injury fear symptoms compared to boys. The results obtained in the study have demonstrated that SCAS has strong psychometric properties. The study on the Turkish version of the scale has provided psychometric information about the fact that the scale can be used in our country.
\end{abstract}

Keywords: anxiety disorders, confirmatory factor analysis, psychometric properties, reliability, validity

\section{INTRODUCTION}

Education is regarded as dispensable factor to obtained a better future. Academic failure has been linked to negative substantial outcomes in childhood (Elmelid, Stickley, Lindblad, Schwab-Stone, Henrich \& Ruchkin, 2015). Academic performance and motivation in school may be affected by symptoms of anxiety (American Psychiatric Association \& DSM-IV Task Force, 2013). According to Malinauskiene, Vosylis and Zakauskiene (2011) anxiety negative related to academic achievement. In this context, understanding the factors of academic perform in school has potentially important implications for the prevention of educational, health and occupational outcomes (Elmelid et al., 2015). Resents years, school-based counselling programs become important in educational system. School-based anxiety programs directly inside the child's environment and trained school staff may play supportive role for children (Manassis, Wilansky-Traynor, Farzan, Kleiman, Parker \& Sanford, 2010). Teachers,

(C) Authors. Terms and conditions of Creative Commons Attribution 4.0 International (CC BY 4.0) apply. Correspondence: Cemaliye Direktör, PhD Candidate, Department of Psychology, European University of Lefke. Lefke, TRNC Mersin 10 Turkey.

$\triangle$ cdirektor@eul.edu.tr 


\section{Contribution of this paper to the literature}

- The aim of this study is to test the validity and reliability of an anxiety scale that children would fill it. It is observed that the Turkish version of the scale provides strong psychometric properties.

- The anxiety scales used in the Turkish language measure cannot provide any information for the younger age group, however gives a measure for general anxiety. Another contribution of this study is that different types of an anxiety can be measured with this scale.

- It is also determined that there is a significant difference between boys and girls in terms of anxiety types.

counsellors and school psychologists were trained to the programs implement as part of the standard school curriculum. Measurements which can examine the anxiety were needed from researchers and teachers.

In the other hand, psychological problems have been widely investigated within the framework of crosscultural studies. In this case, common assessment measurements have to been used. Anxiety disorders are accepted by inter-culturally perspective. In the other hand, there are many cultural differences and cultural differences in responses to survey measurements should be paid attention for anxiety disorders (Baxter, Scott, Vos \& Whiteford, 2013). Anxiety is related to the academic achievement (Lepp, Barkley \& Kaprinski, 2014). Developing countries such as Northern Cyprus, Turkey, Brazil, South Africa and Hong Kong carry out many reforms in order to play a role in the global world (Yüksel, 2014). Educational system is one of the most important factors determining the socio-economic development, so studies on anxiety would be addressed in education and cross-cultural researches in the developing countries.

Anxiety is defined as a tense situation that arises when an event cannot be predicted or it is unsure whether the results will be as desired (Chamsky, 2009). As anxiety is a part of the natural development process, it causes anxiety disorders to be ignored. Researchers often support that anxiety is frequently related to depression, school performance and social life (Gullone, King \& Ollendick, 2001). As can be seen together with other disorders, it also generates significant disadvantages in the field of education (Kendall, 2010). In addition, anxiety is associated with other anxiety disorders. Clinical anxiety is often associated with separation anxiety and social phobia (Weems, Silverman \& La Grece, 2000). Anxiety disorders observed in childhood and adolescence also increase the risk of the incidence of anxiety in adulthood (Pine, Chone, Gurley, Brook \& Ma, 1998). Anxiety disorders are in the first place in Eastern countries as in Western countries (Merikangas, He, Burstein, Swanson, Avenevoli, Cui, Benjet, Georgiades \& Swendsen, 2010).

Anxiety is described as an important feeling experienced as a protective and adaptive function in terms of development experienced throughout life. Anxiety disorders have a structure that disturbs the person, affects his life negatively and disrupts the functionality of life (Karakaya \& Oztop, 2013). In a study on the prevalence of anxiety, it has been found out that $26.6 \%$ of the patients were found to be at risk; $15.8 \%$ had specific phobia, $6.6 \%$ had post-traumatic stress disorder, and $5.6 \%$ had separation anxiety symptoms (Abbo, Kinyanda, Kizza, Levin, Ndyanabangi \& Stein, 2013). The solution to this problem, which is common in children and affects many areas of life, started to gain importance. The anxiety symptoms observed in children and adults differ. Somatic complaints in children (excessive sweating, abdominal pain, irregularities in bowel movements, etc.) are observed more often than those in adults (Karakaya \& Oztop, 2013). It is also unlikely that children will have this awareness when they accept that obsessions or compulsions are excessive or meaningless in relation to the obsessive-compulsive disorder (OCD) (Koroglu, 2007). Anxiety disorders are known to be a major problem beginning in childhood and continuing in adulthood. For example, the annual prevalence of the social phobia varies between $5 \%$ and $10 \%$, and the lifetime prevalence varies between $10 \%$ and $15 \%$ (Ohayon \& Shatzberg, 2010). In a study conducted on school-aged children aged between $4-12$ years, it has been reported that $67.4 \%$ of these children experienced anxiety. In the same study, it has been found that anxiety prevalence increased in line with age (Muris \& Merckelbach, 2000). Conducted studies have shown that anxiety disorders start at an early age and social phobia is the earliest type of anxiety disorder (McEvoy, Grove \& Slade, 2011). It has also been found that social anxiety in children is associated with the lack of desire to go to school and the fall in the academic achievement (Stein \& Kean, 2000). Having analysed the literature, the significance of measuring anxiety disorders increases. While measurement tools that measure anxiety 
are available in research, no scales considering the Diagnostic and Statistical Manual of Mental Disorders (DSMIV) criteria, evaluating anxiety disorders together, and taking into consideration different age groups and gender variables were encountered. In the studies conducted on anxiety disorders, it has been stated that the incidence of anxiety (Gultekin \& Dereboy, 2011) and the symptoms change according to gender. Therefore, the validity and reliability of a scale, distinguishing between normal anxiety and anxiety in childhood, susceptible to gender and age, and evaluating many anxiety problems together, suggest that it will fill an important gap in the field. When the research was examined, it has been observed that the scales regarding anxiety, which were translated into Turkish, measure either a certain characteristic of anxiety or have a parental form. It is believed that the case most frequently seen in children and adolescent psychiatric services is anxiety but the self-report scales are limited, which limits the research to be conducted and it is considered that Spence Child Anxiety Scale will contribute to future work. Although State-Trait Anxiety Inventory (STAI) 1-2 is the most commonly used anxiety scale, this scale is designed for adults and developmental differences are not taken into account. In addition, the sub-dimensions of anxiety are not measured.

The Spence Children's Anxiety Scale (SCAS) was developed by Spence (1998) with the aim of assessing different dimensions of anxiety disorders based on the DSM-IV criteria, taking into account the child development. Separate forms are used for 8-11 years-old children and 12-15 years-old children as well as the child and parental forms. The scale is a 4-point Likert type and consists of 44 items and one open-ended question. Panic attack and agora phobia, separation anxiety, fear of physical injury, social phobia, generalized anxiety and obsessivecompulsive disorder are available as sub-dimensions. It has been found out that the scale was translated into various languages and adapted to different cultures (Essau, Muris \& Ederer, 2002; Essau, Sakano, Ishikawa \& Sasagawa, 2004; Spence, Barrett \& Turner, 2003).

The Australian Cronbach's Alpha value of the SCAS-Child Form was found to be 0.92 (Spence, 1998). In a validity and reliability study conducted on 556 primary school students in Germany, it was found that the scale reliability was 0.92 and the two half reliability was 0.90 . High internal consistency and validity of the scale were supported by various findings. The reliability of the sub-scales varies between 0.57 and 0.82 (Essa et al., 2002). German child form was conducted on 556 primary school students and the consistency was found as .92 while two half reliability was found to be .90 . Internal consistency, test-retest reliability, child-parent relationship, validity, and descriptive qualities were observed to be stronger when SCAS adaptation studies conducted in many different countries were investigated. Whiteside and Brown (2008) indicate that the scale has the character to distinguish between anxious children and non-anxious children. In addition, anxiety is considered to be affected by cultural factors. Erol and Sahin (1995) talk about the widespread fears of death, separation and God in Turkey. In a study looking at the differences in the anxiety scores between China and Germany, it has been stated that Chinese people have significantly higher anxiety scores than Germans (Essau, Leung, Conradt, Cheng \& Wong, 2008).

Orbay and Ayvasik (2006) conducted a preliminary study to translate the parental form of the scale into Turkish, but Cyprus has a bicommunal structure, where two different languages (Turkish and Greek) are used. In addition, there are cultural differences between the Turks in Turkey and in Cyprus. Cyprus was found to be the country with the second highest OCD score among the European countries (Essau, Olaya, Pasha, O'Callaghan \& Bray, 2011; Essau, Sasagawa, Anastassiou-Hadjicharalambous, Guzmán \& Ollendick, 2012).

The factor structure of the SCAS's Brazilian sample for the child form was constructed for both the clinical and the normal group (Desousa Petersen, Behs, Manfro \& Koller, 2012), and the factor structure was examined in Iran. Spence et al. (2003) state that the scale was collected under 6 factors. It has been observed that Essau et al. (2011) obtained a 4-factor structure in their study as social phobia is gathered under one factor with general anxiety. In this context, the aim of this study is to explain the validity and reliability of the SCAS translated into the Turkish language, as well as to test the validity of the 6-factor model in the Turkish Republic of Northern Cyprus (TRNC) population. We translated the SCAS into Turkish with the permission of the original author. Through to use of exploratory and confirmatory factor analysis, the factor structure of the scale in the Turkish culture was assessed. Moreover, another aim of the study is to examine the age and gender patterns of the SCAS and its subscales. 


\section{METHODOLOGY}

\section{Sample}

The sample consists of 461 students studying in the 4th and 5th grade of 11 primary schools selected randomly among 112 primary schools in Nicosia, Morphou, Kyrenia, Famagusta and Iskele districts of the Turkish Republic of Northern Cyprus under the Ministry of National Education. The study was conducted on the 4th and 5 th grades of the primary schools during the course hours of the students. Inform consent form which explains the background of the study and the contact information of the researcher were used to determine the participants. Volunteer participants filled out the inform consent form. All the data were checked before the statistical procedures were performed, and the analysis was performed with 461 data as no missing data were found. $48.80 \%$ of these students were female $(\mathrm{N}=225)$ and $51.20 \%$ were male $(\mathrm{N}=236)$. The age of the children ranged from 9 to $12(X=9.89, S=0.69)$.

\section{Data Collection Tools}

\section{Spence Children's Anxiety Scale (SCAS)}

The Spence Children's Anxiety Scale (SCAS) was developed by Spence (1998) with the aim of assessing different dimensions of anxiety disorders based on the DSM-IV criteria, taking into account the child development. Separate forms are used for 8-11 years-old children and 12-15 years-old children as well as the child and parental forms. SCAS is a 4-point scale and consists of 44 items and one open-ended question. Panic disorder and agoraphobia, separation anxiety, fear of physical injury, social phobia, generalized anxiety and obsessivecompulsive disorder are available as sub-dimensions. Six questions are positive filler items and planned to prevent orientation towards the anxiety problem ones. This measure rates from 0 (never)-3 (always). The maximum score of 114 represents the highest anxiety scale score. A total SCAS score is obtained by summing scores of the 38 anxiety symptom items. Item 45 contains an open-ended question and an additional four-point Likert scale item has been placed to item 45 (Spence, 1998). It has been found out that the scale was translated into various languages and adapted to different cultures (Essau et al., 2002; Essau et al., 2004; Spence et al., 2003).

Cronbach's alpha value of the original form of the scale is reported to be 92 (Spence, 1998). The value of Cronbach's alpha in the adaptation of the adult form of the scale into Spanish was .89 (Orgiles, Mendez, Spence, Medina \& Espada, 2012); the adaptation into Iranian was 92 (Essau, Olaya, Pasha, O'Challaga \& Bray, 2012); the adaptation into German was .92 (Essau, Muris \& Ederer, 2002); the adaptation into Greek was.90 (Mellon \& Moutavelis, 2007); the adaptation into Japanese was .88 (Ishikawa, Oota, \& Sakano, 2001) and the adaptation into South African was .92 (Muris, Schmidt, Engelbrecht, \& Perold, 2002). The Guttman split-half value was reported to be .90 in the German adaptation study (Essau, Muris \& Ederer, 2002).

It has been observed that the effects of the age and gender variables are examined in the studies, in which the psychometric tests related to the scale are made. In the study of Orgiles, Méndez, Spence, Huedo-Medina and Espada (2012), it has been reported that the anxiety scores decreased in line with the age, girls had higher anxiety scores than boys and the relationship between STAI and the total scale score was moderate and significant $(r=.41)$.

\section{State-trait anxiety inventory}

The original form was developed by Spielberger (1973) in order to determine the State and Trait Anxiety levels separately. The scale was adapted into Turkish and reliability and validity studies were conducted by Oner and Le Compte. It consists of two separate scales consisting of 40 items. The first scale measures the state anxiety and the second scale measures the trait anxiety. The total score for each scale ranges from 20 to 80 . Higher scores indicate higher levels of anxiety and lower scores indicate lower levels of anxiety. The Kuder-Richardson (Alpha) reliability of the scale ranged from .83 to .87 , the test-retest reliability ranged from .71 to .86 , and the Item Remainder reliability ranged from .34 to .72 . Structural or experimental concept validity and criterion validity analyses were conducted and satisfactory results were obtained (Oner \& Le Compte 1985) 
Table 1. Language equivalence of the Turkish-English form

\begin{tabular}{llllllc}
\hline & $\mathbf{N}$ & $\mathbf{X}$ & $\mathbf{S S}$ & $\mathbf{T}$ & $\mathbf{d f}$ & $\mathbf{P}$ \\
\hline Turkish & 50 & 70.00 & 11.875 & 0.821 & 49 & .415 \\
\hline English & 50 & 69.28 & 12.349 & & & \\
\hline$p>.05$ & & & & & &
\end{tabular}

\section{Social anxiety scale for children}

It was developed by La Greca, Dandes Wick, Shaw and Stone in 1988. The scale consisting of 10 questions were finalized into the final form of 18 items. The fear of negative evaluation of social anxiety and discomfort in the social environment was evaluated. The scores obtained from the scale ranged from 18 to 90 . The adaptation work into Turkish was performed by Demir, Eralp-Demir, Turksoy, Ozmen and Uysal (1998). The internal consistency of the scale was found to be 0.81 according to the Cronbach's Alpha method. Test-retest correlation was found high $(\mathrm{r}=0.81)$. The validity study was conducted on the social phobia patients admitted to the clinic and it was seen that the scales could be distinguished from the normal controls.

\section{Rosenberg self-esteem scale}

It was developed by Morris Rosenberg in 1963. The validity and reliability study, especially developed for the adolescent age group, was conducted by Cuhadaroglu in 1985 (validity coefficient was 0.71, reliability coefficient was 0.75). It consists of 11 sub-scales, which are self-esteem, continuity of the concept of self, trust in people, sensitivity to criticism, depressive affect, imagination, threatening interpersonal relationships, level of participation in discussions, psychological isolation, psychosomatic symptoms and parental interest. The selfesteem sub-scale consists of ten items that have a positive and a negative meaning. According to the evaluation system of this sub-scale, 0-1 points are evaluated as high, 2-4 points are evaluated as moderate and 5 and higher points are evaluated as high. Accordingly, the high scores achieved by individuals showed that their self-esteem was low.

\section{Process}

The permission for the adaptation of the scale into Turkish was taken. The scale was translated into Turkish by three faculty members at the faculty of the university and by an instructor who taught at the Faculty of English Language Teaching.

An independent evaluation was made by a psychologist, a clinical psychologist and a child and adolescent psychiatrist for the compliance of the Turkish form of the scale. The evaluation of the items in terms of the Turkish language was performed by a scholar from the Turkish Language Department. Five children at different ages were consulted about the clarity of the scale items. In order to look at the conformity of the scale items with their original form, the study was conducted on academicians from different parts of the university, who are native speakers of English, with an interval of three weeks. The academicians were divided into two groups: 25 were firstly given the Turkish form and they were given the English form three weeks later, while the other 25 were firstly given the English form followed by the Turkish form. The relationship between the two scales was found to be .87. The meaning equivalence between English and Turkish forms has been evaluated on the basis of the total scores.

Having the dependent sample t-test results presented in Table 1 examined, it has been determined that there was no significant difference between the two scales when the mean value of Turkish form $(70.00+11.875)$ and the mean value of English form $(69.28+12.349)$ were compared $(t=0.821, p>.05)$.

Following the adaptation of the scale to Turkish, study was conducted on voluntary students at schools during their lessons with the permission of their teachers in accordance with the permission from the Ministry of National Education. In the beginning of the study, the children were given some short information about the scale and then they were asked to fill it in. It was observed that it took 15-20 minutes to fill in. 


\section{RESULTS}

\section{Factor Analysis}

An analysis of the basic components was conducted in order to determine the factor structure of SCAS. The Kaiser Meyer Olkin (KMO) value for assessing the suitability of the sample analysis was determined as .80 (Barlett's; $\left.x^{2}=4.716, p<.001\right)$. Accordingly, it was decided that the data were appropriate for the factor analysis. According to the basic component analysis, eleven factors with an eigenvalue greater than 1 were obtained. The eigenvalues of the factors describing $59.45 \%$ of the total variance are $5.67,3.47,2.47,1.81,1.69,1.61,1.32,1.23,1.18$, 1.08 and 1.04, respectively. When the scree plot was examined, it was decided that it was appropriate to examine 6 factors. When varimax rotation was performed, it was found that 6 factors explained the $44.07 \%$ of the total variance. The first factor explaining $14.94 \%$ of the total variance (Items 36, 34, 21, 37, 32, 30, 13, 28, 39) was called

Table 2. The factor scores of the Turkish version of SCAS by six-factor model

\begin{tabular}{|c|c|c|c|c|c|c|c|}
\hline & & F1 & F2 & F3 & F4 & F5 & F6 \\
\hline Item & 39 & .75 & & & & & \\
\hline Item & 34 & .75 & & & & & \\
\hline Item & 21 & .73 & & & & & \\
\hline Item & 37 & .69 & & & & & \\
\hline Item & 32 & .68 & & & & & \\
\hline Item & 30 & .66 & & & & & \\
\hline Item & 13 & .65 & & & & & \\
\hline Item & 28 & .63 & & & & & \\
\hline Item & 39 & .38 & & & & .37 & \\
\hline Item & 9 & & .69 & & & & \\
\hline Item & 10 & & .65 & & & & \\
\hline Item & 6 & & .62 & & & & \\
\hline Item & 29 & & .54 & & & & \\
\hline Item & 7 & & .47 & & & & \\
\hline Item & 35 & & .46 & & & & \\
\hline Item & 15 & & & .75 & & & \\
\hline Item & 16 & & & .68 & & & \\
\hline Item & 5 & & & .38 & & & \\
\hline Item & 44 & & & .60 & & & \\
\hline Item & 8 & & .34 & .49 & & & \\
\hline Item & 12 & & .33 & .46 & & & \\
\hline Item & 14 & & & & .65 & & \\
\hline Item & 42 & & & & .65 & & \\
\hline Item & 41 & & & & .59 & & \\
\hline Item & 40 & & & & .55 & & \\
\hline Item & 27 & & & & .49 & & \\
\hline Item & 19 & & & & .39 & & \\
\hline Item & 2 & & & & & .64 & \\
\hline Item & 18 & & & & & .64 & \\
\hline Item & 23 & & & & & .57 & \\
\hline Item & 33 & & & & & .57 & \\
\hline Item & 25 & & & & & .46 & \\
\hline Item & 1 & & & & & & .72 \\
\hline Item & 4 & & & & & & .61 \\
\hline Item & 24 & & & & & & .54 \\
\hline Item & 3 & & & & & & .53 \\
\hline Item & 22 & & & & & & .49 \\
\hline Item & 20 & & & & & & .37 \\
\hline
\end{tabular}

Extraction Method: Principal Component Analysis 
panic disorder-agoraphobia; the second factor explaining 9.15\% (Items 9, 10, 6, 29, 7, 35) was called social phobia; the third factor explaining $6.50 \%$ (Items 15, 16, 5, 44, 8, 12) was called separation anxiety; the fourth factor explaining $4.77 \%$ (Items 14, 42, 41, 40, 27, 19) was called obsessive-compulsive disorder; the fifth factor explaining $4.45 \%$ (Items $2,8,23,33,25$ ) was called general anxiety and the sixth factor (Items 1, 4, 24, 3, 22, 20) explaining 4.26\% was called fear of physical injury. Table 2 presented that items 39, 8 and 12 were related to multiple factors when the basic component analysis results were investigated. In order to determine whether an item had a simple structure, the difference between the highest factor load of that item and its load on other factors was studied and it was found below 0.20 (Nunnally and Bernstein, 1994). In this regard, it has been decided that all items had a simple structure.

\section{Reliability of Scale}

The reliability of the scale was tested by both Cronbach's Alpha method and two half-test reliability methods.

Table 3. The reliability values of the items in the Turkish version of SCAS

\begin{tabular}{|c|c|c|c|}
\hline & Corrected Item-Total Correlation & Squared Multiple Correlation & Cronbach's Alpha if Item Deleted \\
\hline Item 1 & .33 & .38 & .83 \\
\hline Item 2 & .27 & .37 & .83 \\
\hline Item 3 & .23 & .23 & .83 \\
\hline Item 4 & .41 & .45 & .83 \\
\hline Item 5 & .32 & .43 & .83 \\
\hline Item 6 & .37 & .32 & .83 \\
\hline Item 7 & .30 & .23 & .83 \\
\hline Item 8 & .38 & .41 & .83 \\
\hline Item 9 & .38 & .41 & .83 \\
\hline Item 10 & .37 & .38 & .83 \\
\hline Item 12 & .34 & .40 & .83 \\
\hline Item 13 & .35 & .40 & .83 \\
\hline Item 14 & .21 & .28 & .83 \\
\hline Item 15 & .32 & .52 & .83 \\
\hline Item 16 & .21 & .39 & .83 \\
\hline Item 18 & .21 & .24 & .83 \\
\hline Item 19 & .25 & .22 & .83 \\
\hline Item 20 & .21 & .22 & .83 \\
\hline Item 21 & .40 & .48 & .83 \\
\hline Item 22 & .45 & .36 & .83 \\
\hline Item 23 & .27 & .24 & .83 \\
\hline Item 24 & .32 & .30 & .83 \\
\hline Item 25 & .23 & .24 & .83 \\
\hline Item 27 & .21 & .26 & .83 \\
\hline Item 28 & .34 & .43 & .83 \\
\hline Item 29 & .40 & .38 & .83 \\
\hline Item 30 & .33 & .43 & .83 \\
\hline Item 32 & .42 & .51 & .83 \\
\hline Item 33 & .27 & .30 & .83 \\
\hline Item 34 & .23 & .54 & .83 \\
\hline Item 35 & .27 & .26 & .83 \\
\hline Item 36 & .42 & .55 & .83 \\
\hline Item 37 & .40 & .47 & .83 \\
\hline Item 39 & .47 & .38 & .83 \\
\hline Item 40 & .21 & .28 & .83 \\
\hline Item 41 & .33 & .34 & .83 \\
\hline Item 42 & .21 & .31 & .83 \\
\hline Item 44 & .39 & .39 & .83 \\
\hline
\end{tabular}


The Cronbach's Alpha value of the scale was .83 and the split half value was .80 . For the reliability of each item, the total item correlation was tested with a square of multiple correlations, and then, the item was subtracted, the reliability was tested by alpha value. Having studied the Table 3, it has been seen that total item correlation values of 14 th, $16 \mathrm{th}, 18 \mathrm{th}, 40$ th and 42 th items were lower than 0.20 . When the multiple correlation values of the items and their alpha values measured after the item exits were examined, it was decided that the items should have been included in the scale.

Having analysed the reliability scores of the sub-scales (Table 4), the panic disorder-agoraphobia sub-scale was determined to be .85 , the social phobia sub-scale was .70 , the separation anxiety sub-scale was .72 , the obsessive-compulsive disorder sub-scale was .62, the physical injury fear sub-scale was .52 and the general anxiety sub-scale was 63.

Table 4. The correlations among the Turkish version of SCAS and subscale scores

\begin{tabular}{|c|c|c|c|c|c|c|}
\hline & 1 & 2 & 3 & 4 & 5 & 6 \\
\hline Total sc. & - & & & & & \\
\hline GA & $.63^{* *}$ & - & & & & \\
\hline $\mathrm{PI}$ & $.49^{* *}$ & $.16^{* \star}$ & - & & & \\
\hline PA & $.63^{* *}$ & $.32^{\star *}$ & $.18^{\star *}$ & - & & \\
\hline OCD & $.47^{* *}$ & $.23^{* *}$ & $.15^{* *}$ & $.17^{* \star}$ & - & \\
\hline SP & $.65^{\star *}$ & $.32^{* *}$ & $.21^{\star \star}$ & $.24^{* *}$ & $.23^{* *}$ & - \\
\hline SA & $.60^{* *}$ & $.26^{* *}$ & $.25^{\star \star}$ & $.14^{\star \star}$ & $.15^{* \star}$ & $.29^{* *}$ \\
\hline
\end{tabular}

$\mathrm{p}^{* * *}<.001 ; \mathrm{p}^{* *}<.01 ; \mathrm{p}^{*}<.05$

GA: General Anxiety, PI: Physical Injury Fear, PA: Panic Disorder and Agoraphobia, OCD: Obsessive-Compulsive Disorder, SP: Social Phobia, SA: Separation anxiety, Total sc.: Total scores of SCAS

\section{Validity of Scale}

The correlation of the test scores with the results of another scale that measures the characteristic to be measured has been defined as the criterion validity (Tanrigen, 2009). In this context, the State-Trait Anxiety Scale was used in order to assess the scale validity, the Spence Children's Anxiety Scale was used in order to test the validity of the sub-scales and the Rosenberg Self-Esteem Scale was used in order to collect information on the correlation between anxiety and self-esteem, which was shown to have negative correlation in the research.

The correlation between the social phobia scores, which is a sub-scale of SCAS, and Social Children's Anxiety Scale were studied and it has observed that the correlation coefficient was found as .523 ( $p<.001)$. It has been determined that there was a slightly low but significant relationship $(r=-.243, p<.001)$ between the total anxiety score and the Rosenberg self-esteem scale scores. Similarly, having studied the relationship between the total anxiety scores and the state trait anxiety scale scores, it has been noted that there was a moderate and significant relationship $(\mathrm{r}=.139, \mathrm{p}<.001)$ between the trait anxiety scale and the Spence Children's Anxiety Scale scores $(\mathrm{r}=$ $.404, \mathrm{p}<.001)$.

\section{Confirmatory Factor Analysis (CFI)}

The results indicated that the measurement model demonstrated an acceptable fit to the data for the sample (Table 5). The chi square of the measurement model was significant $\left(X^{2}(203)=438.74, p<.001\right)$. According to Steiger (1990), the root mean square error of assessing (RMSEA) of the amount of model misfit and it was found to be .069 . The standardized root mean square residual (SRMR) is the average discrepancy between the hypothesized and observed variances and covariance. SRMR was .054 in this model. SRMR values should be .08 or less for a good fitting model (Hu \& Bentler, 1999). The results showed that it was a good fitting model. The CFI of .94 was satisfactory. Additionally, the ratio between chi square and degree of freedom was 2.16 in the study. According to Klein (1998), the ratio between chi square and degree of freedom should be 1 and 3 or less than 3 for a good fitting model. 
Table 5. Summary of the fit indices from measurement model of the Turkish version of SCAS

\begin{tabular}{ccccccccc}
\hline & $\mathbf{X}^{\mathbf{2}}$ & $\mathbf{D f}$ & $\mathbf{X}^{\mathbf{2}} / \mathbf{d f}$ & $\mathbf{R M S E A}$ & $\mathbf{S R M R}$ & CFI & NNFI & GFI \\
\hline CFA & 458.74 & 203 & 2.16 & .069 & .054 & .94 & .93 & .88 \\
\hline
\end{tabular}

The results supported the measurement model of Turkish version of SCAS with six factors in North Cyprus. The results showed that all the path coefficients were significant and had a good fitting to the data.

\section{Gender and Age Effect}

It has been stated that there was a significant difference between girls and boys in terms of the anxiety scores in the original form of the scale and adaptation studies made afterwards (Table 6). Table 6 shows the means and standard deviations of the total SCAS scores and its subscales for the total sample and for gender. The MANOVA revealed a significant multivariate main effect of the gender $\mathrm{F}(1,459)=9.903, \mathrm{p}<.001$. The Wilds' Lamb values were found for the following scales: the total scores of SCAS $=.957$, separation anxiety $=.988$, social phobia $=$ .971 , obsessive-compulsive disorder $=.999$, physical injury fear $=.896$, panic disorder and agoraphobia $=.997$ and general anxiety $=.993$. Significant univariate main effects for gender were obtained for the total scores of SCAS $\mathrm{F}(1,459)=20.462$, $\mathrm{p}<.001$, separation anxiety $\mathrm{F}(1,459)=5.718$, $\mathrm{p}<.05$, social phobia $\mathrm{F}(1,459)=13.887$, $\mathrm{p}<.001$, physical injury fear $\mathrm{F}(1,459)=53.050$, $\mathrm{p}<.001$; no significant gender differences were found for obsessive-compulsive disorder $\mathrm{F}(1,459)=0.406, \mathrm{p}>.05$, panic disorder-agoraphobia $\mathrm{F}(1,459)=1.389, \mathrm{p}>.05$ and general anxiety $\mathrm{F}(1.459)=3.250, \mathrm{p}>.05$. These results suggested that girls had significantly higher levels of anxiety, social phobia and physical injury fear symptoms compared to boys. No significant age differences were found for the total scores and its subscales.

Table 6. The multivariate main effect of gender among the Turkish version of SCAS and subscale scores

\begin{tabular}{|c|c|c|c|c|c|c|}
\hline \multirow{2}{*}{ Variables } & \multicolumn{2}{|c|}{ Girls } & \multicolumn{2}{|c|}{ Boys } & \multicolumn{2}{|c|}{ Total } \\
\hline & Mean & SD & Mean & SD & Mean & SD \\
\hline GA & 12.89 & 3.28 & 12.36 & 3.17 & 12.60 & 3.23 \\
\hline $\mathrm{PI}$ & 10.66 & 3.22 & 8.62 & 2.80 & 9.61 & 3.17 \\
\hline $\mathrm{PA}$ & 14.65 & 4.97 & 14.08 & 5.51 & 14.35 & 5.25 \\
\hline OCD & 15.05 & 3.44 & 14.83 & 3.89 & 14.93 & 3.67 \\
\hline$S P$ & 13.66 & 3.64 & 12.36 & 3.87 & 12.99 & 3.81 \\
\hline SA & 13.19 & 3.97 & 12.28 & 4.13 & 12.72 & 4.07 \\
\hline Total sc. & 80.11 & 13.49 & 74.52 & 13.04 & 77.24 & 13.54 \\
\hline
\end{tabular}

$\mathrm{p}^{* * *}<.001 ; \mathrm{p}^{* *}<.01 ; \mathrm{p}^{*}<.05$

GA: General Anxiety, PI: Physical Injury Fear, PA: Panic Disorder and Agoraphobia, OCD: Obsessive-Compulsive Disorder, SP Social Phobia, SA: Separation anxiety, Total sc.: Total scores of SCAS

Having investigated the age variable, it was concluded that the participants, whose age average was $\mathrm{X}=$ 9.89 , did not make a meaningful difference in terms of the anxiety scores.

\section{DISCUSSION \& CONCLUSION}

Although the Spence Children's Anxiety Scale, created by Spence (1998) taking into consideration the DSM-IV diagnostic criteria, provided models for the formation of different factor structures, a model consisting of 6 factors was taken into account. It has been reported that the general structure of the scale, which was translated into many different languages and adapted culturally, is composed of 6 factors. It has been stated that separation anxiety and fear of physical injury are combined in a single factor in the Turkish preliminary study of the Parental Form (Orbay \& Ayasik, 2006). In the Cypriot sample, it has been seen that the 6-factor structure defined by Spence (1998) is preserved. In the first factor analysis, screen factor was determined by dividing the factor into 11 factors. The factor structures and the distribution of items into factors found in the study are in compliance with the original of the scale. In the German and Japanese adaptations, it has been indicated that 5 factors were obtained and obsessive-compulsive disorder did not distinguish from general anxiety (Essau et al., 2004). In the adaptation made in the Southern Cyprus, 6 factors were reported (Greek). Having evaluated the criterion validity of the scale, it has been found that there was a significant positive correlation between the social phobia scores, which is a sub-scale 
of the SCAS, and the Social Anxiety Scale scores for children. It has been observed that similar results were found in the literature (Orgiles et al., 2012). It has been concluded that there was a negative significant correlation with the Rosenberg Self-Esteem scale and a positive significant correlation with the Continuous Anxiety Scale, which were used for the criterion validity.

The reliability of the scale has been evaluated as quite high in many studies. In the adaptation study, the Cronbach's Alpha value was found as .83 and the Split Half value was found as .80 . The reliability coefficient was considered to be lower than the original scale. It has been seen that the closest value among the adaptation studies is the score of children of this age in Japan, which is similar to the reliability coefficient of the parental form in Turkey. In the German adaptation, the split half value was reported as .90 . Having analysed the reliability scores of the sub-scales, the panic disorder-agoraphobia sub-scale was determined to be .85 , the social phobia sub-scale was .70 , the separation anxiety sub-scale was .72, the obsessive-compulsive disorder sub-scale was .62, the physical injury fear sub-scale was .52 and the general anxiety sub-scale was. 63. Having analysed the German adaptation, it has been observed that the reliability coefficient of panic disorder-agoraphobia was .82 , that of social phobia was .72 , that of separation anxiety was .70, that of obsessive compulsive was .71, that of fear of physical injury was.57 and that of general anxiety was .74 (Essau et al., 2002). It has been identified that sub-scale reliability coefficients were of similar quality.

Having the study analysed in terms of the gender difference, this study revealed similar results with the literature. The original form of the scale (Spence, 1998) and subsequent adaptations indicate that girls have higher anxiety scores than boys (Essau et al., 2004). Similarly, in the Greek adaptation study, it has been stated that girls have higher anxiety points than boys (Mellon \& Moutavelis, 2007). It has been observed that the Social Anxiety, Social Phobia and Physical Injury Fear scores of girls and boys were found to be significantly different but there was no significant difference in the Obsessive-Compulsive Disorder, Panic Disorder and Agoraphobia and General Anxiety sub-scales. Anxiety types are thought to be influenced by cultural values. When the literature is investigated, it has been observed that similar results were obtained. There are many cultural differences for anxiety disorders (Baxter, Scott, Vos \& Whiteford, 2013). In the future researches, it would be better to address the investigation within the framework of cross-cultural studies about children anxiety in developing countries such as Northern Cyprus, Turkey, Brazil, South Africa and Hong Kong.

In the studies conducted with both the child and parental form of the scale, it has been stated that younger children had higher scores than adults (Essau et al., 2004, Nauma et al., 2004). However, no significant difference was found between the groups according to age in this study. This difference can be explained by the fact that the age groups for the study were close to each other.

The results obtained in the study demonstrate that SCAS has strong psychometric properties. The study on the Turkish version of the scale provides psychometric information about the fact that the scale can be used in our country. Due to the fact that the sample is composed of only the normal group, attention should be paid to use it in terms of the informative qualities rather than diagnosing in the clinical use. SCAS is proposed as a scale that can be used in prevalence studies on anxiety disorders, especially for children with anxiety disorders or in studies to be conducted on variables associated with anxiety disorder types. The fact that the scale was formed as a selfreport scale taking into account the developmental characteristics of children with DSM-IV criteria broadens the scope of use of the scale. While professionals in the fields of Psychology, Psychiatry, Education and Child Development are encouraged to take advantage of multiple sources of information, the use of an inventory that the child will answer personally has a major appeal. The scale is suitable to be used by researchers and interested people in line with the indicated recommendations. 


\section{REFERENCES}

Abbo, C., Kinyanda, E., Kizza, R. B., Levin, J., Ndyanabangi, S., \& Stein, D. J. (2013). Prevalence, comorbidity and predictors of anxiety disorders in children and adolescents in rural north-eastern Uganda. Child and adolescent psychiatry and mental health, 7(1), 1-11.

American Psychiatric Association. American Psychiatric Association DSM-5 Task Force. (2013). Diagnostic and Statistical Manual of Mental Disorders: DSM-5. Arlington, VA: American Psychiatric Association.

Baxter, A. J., Scott, K. M., Vos, T., \& Whiteford, H. A. (2013). Global prevalence of anxiety disorders: a systematic review and meta-regression. Psychological medicine, 43(5), 897-910.

Chamsky, T. E. (2009). Çocuklarda Endişe. (E. Kandemir, Trans.) Istanbul: Kuraldışı Yayıncılık.

Cuhadaroglu, F. (1986). Adolesanlarda Benlik Saygısı (Yayınlanmamıs uzmanlık tezi). Hacettepe Üniversitesi Tıp Fakültesi, Psikiyatri Bölümü, Ankara.

Demir, T., Eralp-Demir, D., Turksoy, N., Ozmen, E. \& Uysal, O. (1998). Cocuklar icin sosyal anksiyete olceginin gecerlilik ve güvenilirligi. Çocuk ve Ergen Psikiyatrisi Kongresi, Sapanca.

DeSousa, D. A., Petersen, C. S., Behs, R., Manfro, G. G., \& Koller, S. H. (2012). Brazilian Portuguese version of the Spence Children's Anxiety Scale (SCAS-Brasil). Trends in psychiatry and psychotherapy, 34(3), 147-153.

Elmelid, A., Stickley, A, Lindblad, F., Schwab-Stone, M., Henrich, C. C., \& Ruchkin, V. (2015). Depressive symptoms, anxiety and academic motivation in youth: do schools and families make a difference? Journal of Adolescence, 45,174-182.

Erol, N., \& Sahin, N. (1995). Fears of children and the cultural context: the Turkish norms. European child E adolescent psychiatry, 4(2), 85-93.

Essau, C. A., Leung, P. W., Conradt, J., Cheng, H., \& Wong, T. (2008). Anxiety symptoms in Chinese and German adolescents: Their relationship with early learning experiences, perfectionism, and learning motivation. Depression and Anxiety, 25(9), 801-810.

Essau, C. A., Muris, P., \& Ederer, E. M. (2002). Reliability and validity of the "Spence Children's Anxiety Scale" and the "Screen for Child Anxiety Related Emotional Disorders" in German children. Journal of Behavior Therapy and Experimental Psychiatry, 33, 1-18.

Essau, C. A., Olaya, B., Pasha, G., O'Callaghan, J., \& Bray, D. (2012). The structure of anxiety symptoms among adolescents in Iran: A confirmatory factor analytic study of the Spence Children's Anxiety Scale. Journal of anxiety disorders, 26(8), 871-878.

Essau, C. A., Sakano, Y., Ishikawa, S., \& Sasagawa, S. (2004). Anxiety symptoms in Japanese and in German children. Behaviour Research and Therapy, 42, 601-612.

Essau, C. A., Sasagawa, S., Anastassiou-Hadjicharalambous, X., Guzmán, B. O., \& Ollendick, T. H. (2011). Psychometric properties of the Spence Child Anxiety Scale with adolescents from five European countries. Journal of Anxiety Disorders, 25(1), 19-27.

Gullone, E., King, N. S. \& Ollendick, T. H. (2001). Self-Reported Anxiety in Children and Adolescents: A ThreeYear Follow-Up Study. The Journal of Genetic Psychology, 162(1), 5-19.

Gultekin, B. K., \& Dereboy, I. F. (2011). The prevalence of social phobia, and its impact on quality of life, academic achievement, and identity formation in university students. Turk Psikiyatri Dergisi, 22(3), 150.

Ishikawa, S., Ota, R., \& Sakano, Y. (2001). Development of the Japanese version of Spence Children's Anxiety Scale. Waseda Journal of Clinical Psychology, 1, 75-84.

Karakaya, E., \& Oztop, D. B. (2013). Kaygı bozukluğu olan çocuk ve ergenlerde bilişsel davranışçı terapi. Bilişsel Davranışçı Psikoterapi ve Araştırma Dergisi, 2, 10-24.

Kendall, P. C. (Ed.). (2011). Child and adolescent therapy: Cognitive-behavioral procedures. Guilford Press.

La Greca, A. M., Dandes, S. K., Wick, P., Shaw, K., \& Stone, W. L. (1988). Development of the Social Anxiety Scale for Children: Reliability and concurrent validity. Journal of Clinical Child Psychology, 17(1), 84-91.

Lepp, A., Barkley, J. E., \& Karpinski, A. C. (2014). The relationship between cell phone use, academic performance, anxiety, and satisfaction with life in college students. Computers in Human Behavior, 31, 343-350. 
Malinauskine, O., Vosylis, R., \& Zukauskiene, R. (2011). Longitudinal examination of relationships between problem behaviours and academic achievement in young adolescents. Procedia Social and Behavioral Sciences, 15, 3415-3421.

Manassis, K., Wilansky-Traynor, P., Farzan, N., Kleiman, V., Parker, K., \& Sanford, M. (2010). The feelings club: randomized controlled evaluation of school-based CBT for anxious or depressive symptoms. Depression and Anxiety, 27, 168-179.

McEvoy, P. M., Grove, R., \& Slade, T. (2011). Epidemiology of anxiety disorders in the Australian general population: findings of the 2007 Australian National Survey of Mental Health and Wellbeing. Australian and New Zealand Journal of Psychiatry, 45(11), 957-967.

Mellon, R. C., \& Moutavelis, A. G. (2007). Structure, developmental course, and correlates of children's anxiety disorder-related behavior in a Hellenic community sample. Journal of Anxiety Disorders, 21(1), 1-21.

Merikangas, K. R., He, J. P., Burstein, M., Swanson, S. A., Avenevoli, S., Cui, L., Benjet, C., Georgiades, K. \& Swendsen, J. (2010). Lifetime prevalence of mental disorders in US adolescents: results from the National Comorbidity Survey Replication-Adolescent Supplement (NCS-A). Journal of the American Academy of Child $\mathcal{E}$ Adolescent Psychiatry, 49(10), 980-989.

Muris, P., \& Merckelbach, H. (2000). Fears, Worries and Scary Dreams in 4-to-12 Years Old Children: Their Content, Developmental Pattern, and Origins. Journal of Clinical Child Psychology, 29(1), 43-53

Muris, P., Schmidt, H., Engelbrecht, P., \& Perold, M. (2002). DSM-IV-defined anxiety disorder symptoms in South African children. Journal of the American Academy of Child \& Adolescent Psychiatry, 41, 1360-1368.

Nunnally, J. C., \& Bernstein, I. H. (1994). Psychometric theory (3rd Ed). New York: McGraw-Hill Inc.

Ohayon, M. M., \& Schatzberg, A. F. (2010). Social phobia and depression: prevalence and comorbidity. Journal of Psychosomatic Research, 68(3), 235-243.

Oner, N., \& Le Compte, A. (1983). Süreksiz Durumluk/Sürekli Kaygı Envanteri El Kitabı. Istanbul: Boğaziçi Yayınları.

Orbay, O., \& Ayvasik, H. B. (2006). Spence çocuklar için kaygi ölçeği-ebeveyn formu: ön çalişma. Türk Psikoloji Yazilari, 9(18), 33-48

Orgilés, M., Méndez, X., Spence, S. H., Huedo-Medina, T. B., \& Espada, J. P. (2012). Spanish validation of the Spence Children's Anxiety Scale. Child Psychiatry \& Human Development, 43(2), 271-281.

Pine, D. S., Chone, P., Gurley, D., Brook, J., \& Ma, Y. (1998). The risk for early-adulthood anxiety and depressive disorders in adolescents with anxiety and depressive disorders. Archives of General Psychiatry, 55, 56-64

Spence, S. H. (1998). A measure of anxiety symptoms among children. Behaviour research and therapy, 36(5), 545-566.

Spence, S. H., Barrett, P. M., \& Turner, C. M. (2003). Psychometric properties of the Spence Children's Anxiety Scale with young adolescents. Journal of Anxiety Disorders, 17, 605-625.

Spielberger, C. D. (1973). Manual for State-Trait Anxiety Inventory for children. Palo Alto: Consulting Psychologist Press.

Stein, M. B., \& Kean, Y. M. (2000). Disability and quality of life in social phobia: Epidemiologic findings. American Journal of Psychiatry, 157, 1606-1613.

Weems, C. F., Silverman, W. K., \& La Grece, A. M. (2000). What do you the effered for anxiety problems worry about? Worry and its relation to anxiety and anxiety disorders in children and adolescents. Journal of Abnormal Child Psychology, 28, 63-72.

Whiteside, S. P., \& Brown, A. M. (2008). Exploring the utility of the Spence Children's Anxiety Scales parent-and child-report forms in a North American sample. Journal of Anxiety Disorders, 22, 1440-1446.

Yüksel, H. G. (2014). Becoming a teacher: tracing changes in pre-service English as a foreign language teachers' sense of efficacy. South African Journal of Education, 34(4), 1-8.

\section{http://www.ejmste.com}

